\title{
Study of the Structure of Free Radicals in Gamma - Irradiated Amino Acid Derivatives
}

\author{
Murat AYDIN* \\ Faculty of Education, Adiyaman University, TR 02030-Adiyaman, Turkey
}

(Received on 5 August, 2010)

\begin{abstract}
Electron paramagnetic resonance spectroscopy has been used for the study of the free radicals produced in the powders of L-arginine monohydrochloride, ala-ala and DL- $\beta$-leucine gamma-irradiated at room temperature. The structures of the radicals formed in compounds were determined as $\mathrm{NH}_{2}(\mathrm{NH}) \mathrm{NHC} \mathrm{HCH}_{2} \mathrm{CH}_{2} \mathrm{CH}\left(\mathrm{NH}_{2}\right) \mathrm{COOH}, \mathrm{CH}_{3} \dot{\mathrm{C}} \mathrm{HCOOH}$ and $\left(\mathrm{CH}_{3}\right)_{2} \dot{\mathrm{CCH}}\left(\mathrm{NH}_{2}\right) \mathrm{CH}_{2} \mathrm{COOH}$ respectively. The paramagnetic species were found to be stable at room temperature more than three months. It was determined that unpaired electron interacted with nearby protons and ${ }^{14} \mathrm{~N}$ nucleus in these radicals. The $g$ values of the radicals and the hyperfine structure constants of the free electron were also measured. These results were compared with the earlier studies in amino acid and derivatives radicals and discussed.
\end{abstract}

Keywords: EPR, Free radicals, Gamma irradiation, Amino acids compounds

\section{INTRODUCTION}

Free radicals play an important role in biological process and they have a vital importance for the health of the living organisms $[1,2]$. It is known that electron paramagnetic resonance (EPR) spectroscopy is one of the most powerful methods for studying the structure and determining the identity of free radicals [3]. An interpretation of the EPR spectrum is generally accomplished after the determination of a set of spin Hamiltonian parameters. The magnetic properties of many organic substances have been investigated using the EPR technique [4 - 10]. The EPR of gamma-irradiated powders of $\mathrm{N}$-acetyl-L-arginine and $\mathrm{N}_{\alpha}$-carbamyl-L-arginine were studied by Zincircioglu et al. [11] at room temperature. Furthermore, in the gamma-irradiated single crystal of Nacetyl-L-Leucine, at room temperature, the free radicals have

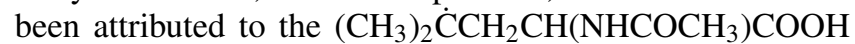
and $\left(\mathrm{CH}_{3}\right)_{2} \mathrm{CHCH}_{2} \dot{\mathrm{C}}\left(\mathrm{NHCOCH}_{3}\right) \mathrm{COOH}$ radicals [12].

Arginine, ala-ala and leucine are biologically important compounds. Therefore the purpose of this work is to investigate the defects induced by gamma-irradiation in powders of L-arginine monohydrochloride (LAMHCl), ala-ala, DL$\beta$-leucine (DLBL) and to determine their spin Hamiltonian parameters at room temperature.

\section{EXPERIMENTAL}

The samples used in this study were obtained from commercial sources. Powder samples of the compounds were irradiated at room temperature with a ${ }^{60} \mathrm{Co}$ gamma-ray source (Nordion-Canada model JS 9600) of $30 \mathrm{kGy}$. After irradiation, samples were kept in plastic bags at room temperature in the dark. The spectra of samples were recorded by putting the sample in quartz sample tube. The EPR measurements was carried out in a Varian model X-band E-109C EPR spectrometer at room temperature. The modulation amplitude was below $5.10^{-2} \mathrm{mT}$ and the microwave power was $2 \mathrm{~mW}$. The $g$ factors were found by comparison with a dipenhylpicrylhydrazyl (DPPH) sample with of $g=2.0036$ [13].

*Electronic address: maydin@adiyaman.edu.tr
The spectrum simulations were made using McKelvey's programs [14].

\section{RESULTS AND DISCUSSION}

Figure 1 presents the EPR spectrum of LAMHCl powder, gamma-irradiated and recorded at room temperature. This spectrum has approximately $1: 2: 2: 2: 1$ intensity ratio, and can be attributed to the $\mathrm{NH}_{2}(\mathrm{NH}) \mathrm{NHC} \mathrm{HCH}_{2} \mathrm{CH}_{2} \mathrm{CH}\left(\mathrm{NH}_{2}\right) \mathrm{COOH}$ radical. It can be seen that it consists of a doublet with a spacing of $2.10 \mathrm{mT}$. Then each line of doublet is further subdivided into three lines of spacing with $1.12 \mathrm{mT}$, with an intensity distribution of 1:2:1. A spectrum for a larger number of inequivalent protons can be found by graphic construction, which is a mathematical record of an EPR spectrum [15]. The binomial expansion for this spectrum is given as:

$$
1: 2: 1+1: 2: 1=1: 2: 2: 2: 1 \text {. }
$$

Similar EPR spectrum and intensity distribution were observed for the gamma-irradiated L-arginine powders at room temperature [16]. In this case, the same radical produced by the abstraction of one hydrogen atom form the same carbon atom. A simulation of the LAMHCl spectrum is shown figure $1 \mathrm{~b}$, using the hyperfine coupling constants $a_{\alpha}=2.10 \mathrm{mT}$, $a_{\beta}=1.12 \mathrm{mT}$ and $a_{N}=0.28 \mathrm{mT}$. The linewidth of the spectrum is somewhat larger than the hyperfine coupling constant of the nitrogen nuclei, and therefore the hyperfine splitting of the nitrogen nuclei is not observed in the spectrum. The measured $g$ value of the radical is $g=2.0028 \pm 0.0005$. It is known that the value of the $g$ factor in aliphatic aminoalkyl radicals vary between 2.0027 - 2.0031 [17]. The $g$ value in this study is in this range.

The gamma-irradiated powder of ala-ala gives the spectrum indicated in figure 2 , at room temperature. When this spectrum is examined throughly, it can be seen that it consists of five lines the intensity ratio $1: 4: 6: 4: 1$. The unpaired electron interacts with one proton directly attached to the $\alpha$ carbon atom and three protons of the freely rotating methyl groups, which is magnetically approximately equal. According to these results, the radical must be $\mathrm{CH}_{3} \dot{\mathrm{C}} \mathrm{HCOOH}$. The measured values of hyperfine coupling constants and the $g$ factor are $a_{\alpha}=2.02 \mathrm{mT}, a_{\beta}=2.24 \mathrm{mT}$ and $g=2.0041 \pm$ 


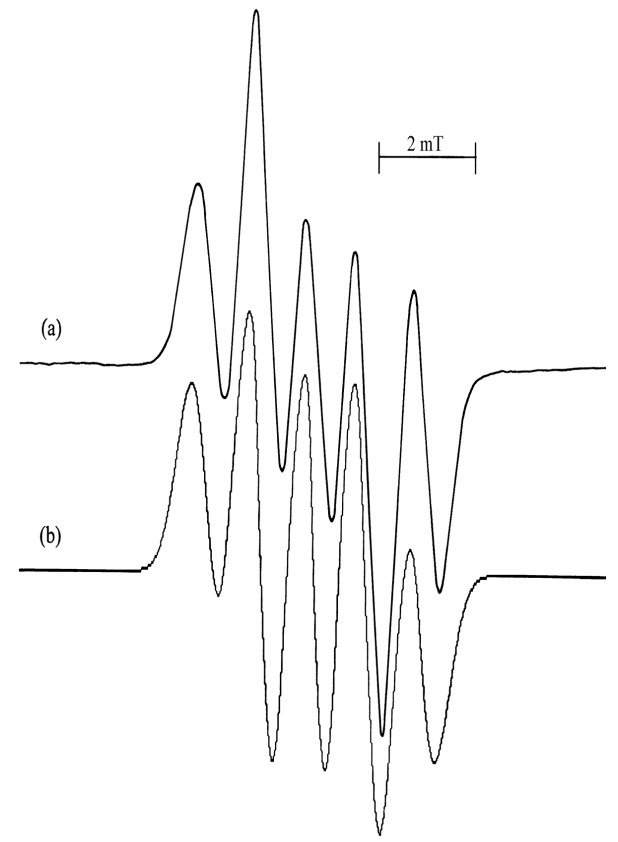

FIG. 1: (a) The EPR spectrum of gamma-irradiated LAMHCL powder at room temperature, (b) simulation form of the spectrum using $a_{\alpha}=2.10 \mathrm{mT}, a_{\beta}=1.12 \mathrm{mT}, a_{N}=0.28 \mathrm{mT}$ and linewidth $0.32 \mathrm{mT}$.

0.0005. The $g$ value of the radical is similar to those where the unpaired electron is placed on the carbon atoms [18]. A spectrum simulated with the above given values agrees with the experiment (Figure 2b).

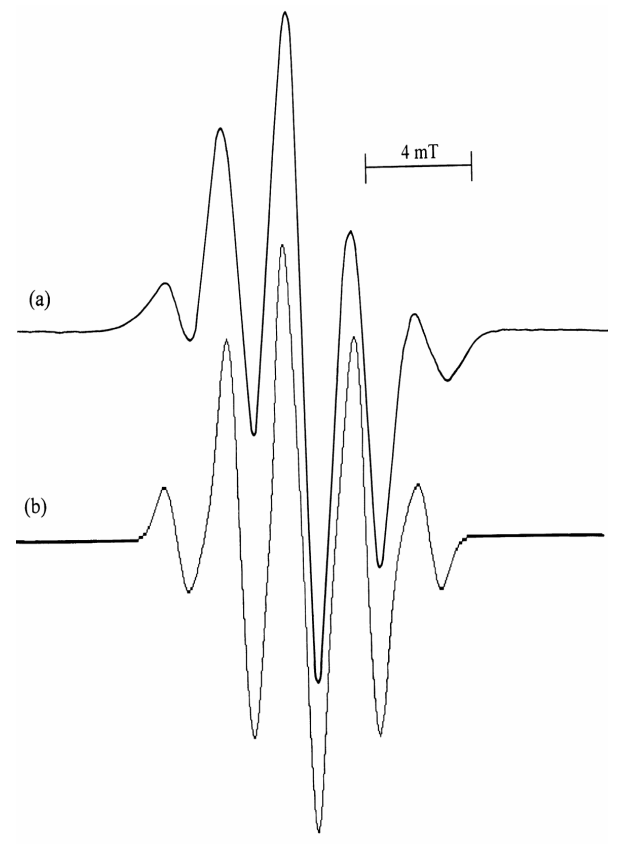

FIG. 2: (a) The EPR spectrum of gamma-irradiated ala-ala powder at room temperature, (b) simulation form of the spectrum using $a_{\alpha}=2.02 \mathrm{mT}, a_{\beta}=2.24 \mathrm{mT}$ and linewidth $0.46 \mathrm{mT}$.

The EPR parameters of the radical discussed here agree with the values measured in the irradiated alanine and their derivatives [11, 16, 19 - 21]. X-irradiated L-alanine single crystal has been investigated by EPR technique, and the reported values of the hyperfine coupling constants are $a_{\alpha}=$ $1.51 \mathrm{mT}, a_{\beta}=1.88 \mathrm{mT}$ at low temperature and $a_{\alpha}=2.14$ $\mathrm{mT}, a_{\beta}=2.38 \mathrm{mT}$ at room temperature [22]. The measured values at room temperature are in agreement with our results. The amine group abstraction is one of the most common mechanisms of producing free radicals in alanine compounds [23 - 25].

The EPR spectrum of DLBL in figure 3 exhibits an intensity distribution as $1: 6: 15: 20: 15: 6: 1$. This spectrum belongs to the $\left(\mathrm{CH}_{3}\right)_{2} \dot{\mathrm{CCH}}\left(\mathrm{NH}_{2}\right) \mathrm{CH}_{2} \mathrm{COOH}$ radical due to the hyperfine interactions of the unpaired electron with six equivalent protons of the two methyl groups, one $\mathrm{CH}$ proton and ${ }^{14} \mathrm{~N}$ nucleus. A simulation of the spectrum is shown figure $3 \mathrm{~b}$, using the hyperfine coupling constants $a_{\left(\mathrm{CH}_{3}\right)_{2}}=2.10$ $\mathrm{mT}, a_{C H}=0.63 \mathrm{mT}, a_{N}=0.52 \mathrm{mT}$ and linewidth $0.46 \mathrm{mT}$. The $g$ value of the radical is measured as $g=2.0028 \pm$ 0.0005 . Since the linewidth of the spectrum is fairly large, the hyperfine splitting of the $\mathrm{CH}$ proton and the nitrogen nuclei are not observed in the spectrum. It can be state that this radical is obtained by the removal of hydrogen atom from the tertiary carbon atom of the DLBL.

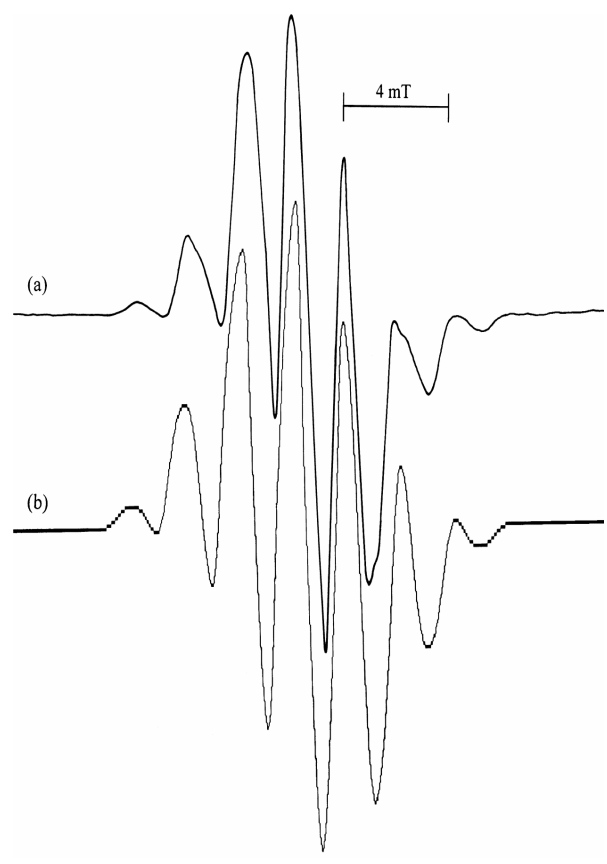

FIG. 3: (a) The EPR spectrum of gamma-irradiated DLBL powder at room temperature, (b) simulation form of the spectrum using

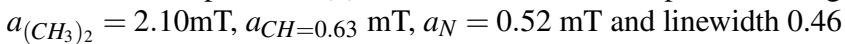
$\mathrm{mT}$.

The measured hyperfine coupling constants of the methyl protons and the $g$ value for this radical are in agreement with those of the radicals which are derived from leucine and valine [26 - 29]. In gamma-irradiated L-valine methyl ester hydrochloride powder, at room temperature, the free radical has been attributed to the $\left(\mathrm{CH}_{3}\right)_{2} \dot{\mathrm{CCH}}\left(\mathrm{NH}_{3} \mathrm{Cl}\right) \mathrm{COOCH}_{3}$ radical [30]. This is similar to our proposed radical and the reported values of $a_{\left(\mathrm{CH}_{3}\right)_{2}}=2.39 \mathrm{mT}, a_{\mathrm{CH}}=0.61 \mathrm{mT}$ and $a_{N}=0.61 \mathrm{mT}$ are in good agreement with our resuls. In the $\left(\mathrm{CH}_{3}\right)_{2} \mathrm{CCH}\left(\mathrm{NH}_{2}\right) \mathrm{CH}_{2} \mathrm{COOH}$ radical, we can state that the 
unpaired electron is localized at the carbon atom binding the two methyl groups.

\section{CONCLUSION}

In this study, we have been indicated that the structure and the identity of the free radicals trapped in the LAHCl, ala-ala and DLBL have been investigated using an EPR technique. The EPR parameters of these radicals could be determined and these values were found to be consistent with previous results in the literature. The measurements of magnetic properties of these radicals can be helpful in the study of similar radicals found in biological systems.

\section{Acknowledgments}

This work was supported by Grant No. EFBAP2009-0005 of the Research Fund of Adiyaman University (ADYAP).
[1] N. D. Yordanov and R. Mladenova, Int. J. Food Sceince Tech., 42, 1384 (2007).

[2] T. Kiljunen, E. Popov, H. Kunttu, J. Eloranta, J. Chem. Phys., 130, 164504 (2009).

[3] U. Sayin, E. Türkan, Ö. Dereli, H. Yüksel, M. Birey, Radiat. Phys. Chem., 79, 863 (2010).

[4] [4] B. Karabulut, R. Tapramaz, Radiat. Phys., 55, 331 (1999).

[5] N. D. Yordanov and B. Mladenova, Radiat. Phys. Chem., 60, 191 (2001).

[6] N. D. Yordanov, R. Mladenow, Spectrochim. Acta A, 60, 1395 (2004).

[7] M. Tabak, D. de Sousa Neto and C.E.G. Salmon, Braz. J. Phys., 36, 83 (2006).

[8] Kinoshita, L. Figuty and O. Baffa, Braz. J. Phys., 36, 93 (2006).

[9] M. Aydin, M.H. Basksan, Y. E. Osmanoglu, Braz. J. Phys., 39, 583 (2009).

[10] M. Aydin, S. Osmanoðlu, M.H. Baskan, I.Y. Dicle, J. Mol. Struct., 975, 30 (2010).

[11] S.B. Zincircioglu, N. Canoruc, S. Osmanoglu, M.H. Baskan, I.Y. Dicle, M. Aydin, Z. Naturforsch., 61a, 577 (2006).

[12] ] G.A. Almanov, G.A. Bogdanchikov, O.M. Usov, Radiat. Phys. Chem., 29, 75 (1987).

[13] N. D. Yordanov, Appl. Mag. Res., 10, 339 (1996).

[14] R.D. McKelvey, J. Chem. Educ., 64, 497 (1987).

[15] M. Birey, Z. Naturforsch., 57a, 36 (2002).
[16] M. Aydin, M.H. Baskan, S. Yakar, S.F. Ulak, M. Aydınol, B. Aydınol, M. Büyüm, Radiat. Eff. Defect. Solids, 163, 41 (2008).

[17] R. Köseoglu, E. Köseoglu, F. Köksal, App. Radiat. Isot., 58, 63 (2003).

[18] L. Horvath, V.H. Laslo, H. Bilinsky, Radiat. Phys. Chem., 32 , 801 (1988).

[19] A. Horsfield, J.R. Morton, D.H. Whiffen, Mol. Phys., 4, 425 (1961).

[20] J.R. Morton, A. Horsfield, J. Chem. Phys., 35, 1142 (1961).

[21] A. Horsfield, J.R. Morton, D.H. Whiffen, Mol. Phys., 5, 115 (1962).

[22] J.W. Sinclair, M.W. Hanna, J.Phys. Chem., 71, 84 (1967).

[23] I. Miyagawa, W. Gordy, J. Chem. Phys., 32, 255 (1960).

[24] W.C. Lin, C.A. Mcdowell, Can. J. Chem., 40, 1062 (1962).

[25] E. Sagstuen, E. O. Hole, S. R. Haugedal, W. H. Nelson, J. Phys. Chem. A, 101, 9763 (1997).

[26] G.H. Schnepel, Int. J. Rad. Biol., 25, 555 (1974).

[27] G.A. Almanov, G.A. Bogdanchikov, O.M. Usov, J. Structural Chem., 36, 912 (1989).

[28] V . N. Laslo, T. A. Himdan, H. Bilinski, Radiat. Res., 132, 1 (1992).

[29] M. Aydin, Braz. J. Phys., 40, 306 (2010).

[30] I. Kartal, F. Kksal, F. Ucun, J. Chem. Res. (S), 118 (1996). 